\title{
Hepatic manifestations of celiac disease
}

This article was published in the following Dove Press journal:

Clinical and Experimental Gastroenterology

30 April 2010

Number of times this article has been viewed

\section{Hugh James Freeman \\ Department of Medicine (Gastroenterology), University of British Columbia,Vancouver, British Columbia, Canada}

Correspondence: Hugh J Freeman UBC Hospital, 221 I Wesbrook Mall, Vancouver, BC, Canada V6T IW5

Tel +6048227216

Fax +604 8227236

Email hugfree@shaw.ca
Abstract: Different hepatic and biliary tract disorders may occur with celiac disease. Some have been hypothesized to share genetic or immunopathogenetic factors, such as primary biliary cirrhosis, primary sclerosing cholangitis, and autoimmune hepatitis. Other hepatic changes in celiac disease may occur with malnutrition resulting from impaired nutrient absorption, including hepatic steatosis. In addition, celiac disease may be associated with rare hepatic complications, such as hepatic T-cell lymphoma.

Keywords: celiac disease, autoimmune liver disease, primary biliary cirrhosis, fatty liver, gluten-free diet

\section{Introduction}

Several hepatobiliary disorders occur in celiac disease, a genetically-based small bowel disorder that resolves with the complete restriction of dietary gluten. ${ }^{1}$ Almost three decades ago, changes in the liver were first recognized in celiac disease. ${ }^{2}$ Later, these observations were prospectively confirmed and findings were extended to effects induced by treatment with a gluten-free diet. ${ }^{3}$ In some, hepatic changes entirely reversed after a gluten-free diet, while in others, clinically significant liver disease was not corrected by diet alone. ${ }^{3}$ Overall recognition of celiac disease has been improved in recent years, in large part related to development and application of modern serological assays for celiac screening. ${ }^{4-6}$ Likely, as a result, more precise estimates of overall liver disease burden in celiac disease will emerge. Indeed, in a recent extensive population-based study from Sweden, individuals with celiac disease were found to be at increased risk for both prior and subsequent liver disease, however, the risk of liver transplantation was not increased. ${ }^{7}$

If unexplained elevations of liver enzymes occur, almost $10 \%$ will prove to have celiac disease. ${ }^{8,9}$ In 55 patients with increased liver chemistry tests, in the absence of other known cause, endomysial and gliadin antibodies were examined. ${ }^{8}$ Five patients were sero-positive and small bowel biopsies showed changes of celiac disease that responded to a gluten-free diet. In a further investigation, liver biopsies revealed a non-specific inflammatory process and liver chemistry tests normalized with a gluten-free diet. In 140 patients with chronic elevation of transaminase values, gliadin and endomysial antibodies were positive in 13 cases. ${ }^{9}$ After one year on a gluten-free diet, 12 had normalization of liver enzyme tests. ${ }^{9}$

In already documented celiac disease, abnormal liver enzyme tests may also be present. ${ }^{2,10-12}$ Elevated liver enzymes were recorded in 30 of 75 patients, or almost $40 \%{ }^{2}$ 
Others showed increased levels in 39 of 65 children, or about $60 \% .^{10}$ Later, about $50 \%$ of celiacs had increased liver enzyme values. ${ }^{11}$ In some, a liver biopsy revealed an entirely non-specific inflammatory process although a more specific label of "chronic active hepatitis" was provided in five of 37 patients, or $13.5 \%$. Finally, 158 consecutive adults with celiac disease were reported with $42 \%$ having abnormal liver enzyme levels. A gluten-free diet ranging from 1-10 years resulted in complete normalization of liver chemistry tests in $95 \% .^{12}$

Not all studies have demonstrated completely normal liver chemistry results after institution of a gluten-free diet in all patients. This may reflect, in part, the heterogeneous nature of celiac disease. For instance, in some, involvement along the length of the small bowel may be extensive, while in others, changes may be limited to the proximal small bowel alone. In some studies, different durations of exposure to a gluten-free diet may have been critical before liver chemistry tests were observed to normalize. Other factors may play a role. For example, Selcuk et al noted a case with apparent progression of liver disease from steatosis to steatohepatitis associated with weight gain on gluten-free diet, possibly related to development of a metabolic syndrome. ${ }^{13}$ A concomitant infection, such as hepatitis $\mathrm{C}^{14}$ could play a role, possibly through a molecular-mimicry-like pathogenetic mechanism suggested for adenovirus 12 in celiac disease, ${ }^{15}$ but others have concluded that no clear correlation is evident. ${ }^{16-18}$ Alternatively, treatment of hepatitis $\mathrm{C}$ with interferon/ribavirin has been hypothesized to activate celiac disease, ${ }^{19}$ prompting some to raise the issue of routine screening for celiac disease prior to anti-viral treatment. ${ }^{20}$ Finally, celiac disease has also been detected after orthotopic liver transplantation in a case of hepatitis $\mathrm{C}$ associated cirrhosis. ${ }^{21}$

Persistent abnormalities in liver chemistry tests may also be due to a clinically occult, but specific hepatobiliary tract disorder sharing common immunopathogenetic features with celiac disease. Examples of immune-mediated disorders include primary biliary cirrhosis, autoimmune (lymphocytic) sclerosing cholangitis, or autoimmune hepatitis. Moreover, in hemochromatosis, a genetically-based disorder with altered control of small intestinal iron absorption with concomitant iron overload, celiac disease has been recorded. In addition, chronic changes in liver chemistry tests may reflect a direct effect of celiac disease on the liver per se. For example, impaired absorption and resultant malnutrition may lead to abnormal hepatic fat deposition, related, in part, to impaired fat mobilization from hepatocytes. In fact, even massive hepatic steatosis has been reported in celiac disease. Finally, but very rarely, patients may develop a specific complication of celiac disease that involves the liver, such as malignant lymphoma, including a specific, but rare T-cell type, hepatosplenic lymphoma.

\section{Primary biliary cirrhosis}

In 1978, primary biliary cirrhosis was described with celiac disease. ${ }^{22}$ Later, additional cases were described. ${ }^{23-25}$ For both primary biliary cirrhosis and celiac disease, other concomitant immune-mediated conditions were noted, including diabetes and thyroiditis. ${ }^{25-28}$ In addition to reports from Europe and the Americas, concurrent primary biliary cirrhosis and celiac disease was also noted in South Asians ${ }^{29}$ and the Coast Salish, an aboriginal population in Canada, believed to be of Asian descent. ${ }^{26}$ Weight loss, malabsorption, osteopenic bone disease, steatorrhea, and elevated alkaline phosphatase levels are common in both disorders. As a result, celiac disease and primary biliary cirrhosis may be difficult to recognize as two distinct disorders, especially early in their clinical onset. Restriction of dietary gluten may improve the celiac disease, but usually, abnormal liver chemistry tests persist suggesting that the liver disease is not affected.

More recent studies have explored serological screening in both diseases. Using a patient registry in the United Kingdom, ${ }^{30}$ the prevalence of primary biliary cirrhosis was defined in 143 celiac patients as 3\%, while the prevalence of celiac disease in 67 primary biliary cirrhosis patients was $6 \%$. As a result, screening with antimitochrondrial antibodies in celiac disease was recommended, while in primary biliary cirrhosis, serological screening with gliadin antibodies or small intestinal biopsy was suggested. ${ }^{31}$ Similar findings of $7 \%$ of 57 primary biliary cirrhosis patients were noted based on initial evaluation using endomysial antibodies (11\% positive) followed by later duodenal biopsy confirmation. Despite 12 to 24 months on gluten-free diets, however, improvement in liver chemistry tests was not detected even though endomysial antibodies disappeared. Using Danish and Swedish registry data based on over 8000 patients with celiac disease, an increased risk of primary biliary cirrhosis was also suggested. ${ }^{32}$ Later, stored sera from 378 Canadian patients with primary biliary cirrhosis were employed to screen for celiac disease in our laboratory. ${ }^{33}$ Both IgA antibodies to endomysium and tissue transglutaminase were positive in 10 patients $(2.6 \%)$. Of these, five patients had small bowel biopsies confirming celiac disease. An additional 44 primary biliary cirrhosis patients had raised IgA tissue transglutaminase antibodies, but the same sera were 
negative for IgA endomysium antibodies. In 255 patients with autoimmune cholestatic liver disorders (including 173 with primary biliary cirrhosis), a different investigative group ${ }^{34}$ found nine with celiac disease (including seven in those with primary biliary cirrhosis, or 4\%). Finally, the importance of biopsy confirmation in primary biliary cirrhosis was noted as false-positive IgA or IgG-tTG antibodies may occur in primary biliary cirrhosis. ${ }^{35,36}$

In a later study using a general practice longitudinal database from the United Kingdom, ${ }^{37}$ an overall three-fold risk of primary biliary cirrhosis was demonstrated in 4,732 patients diagnosed with celiac disease compared to 23,620 age- and sex-matched controls.

\section{Primary sclerosing cholangitis}

In 1988, primary sclerosing cholangitis was linked to celiac disease in three patients with diarrhea and steatorrhea. ${ }^{38}$ Two also had concomitant "ulcerative colitis" known to be associated with primary sclerosing cholangitis. In these, hepatic and biliary tract changes were defined by liver biopsy and cholangiograms, but these did not respond to a gluten-free diet. Subsequent reports have described other cases. ${ }^{11,34,39-42}$ In one, the predominant lymphocytic nature of the portal tract inflammatory process was noted with increased intra-epithelial lymphocytes in biliary ductal epithelium, ${ }^{42}$ also noted in gastric and colonic epithelium of celiac patients. ${ }^{43,44}$ Another patient with sclerosing cholangitis in celiac disease developed a cholangiocarcinoma. ${ }^{45}$ To date, however, it has been difficult to confirm any definitive hepatobiliary tract response to a gluten-free diet. In part, this may reflect sampling error associated with liver biopsy as well as the limited specificity of liver chemistry test markers for cholestasis (eg, serum alkaline phosphatase). Indeed, the origin of serum alkaline phosphatase in this setting may include the hepatobiliary tract as well as other sources (eg, bone, intestine). Each of these sources might be substantially altered in celiac disease, and potentially improved with a gluten-free diet.

\section{Autoimmune hepatitis and cholangitis}

This has been noted in limited case reports and survey studies. ${ }^{4-49}$ Unfortunately, many appeared before hepatitis $\mathrm{C}$ testing. ${ }^{46,47}$ In one, liver biopsies were done in 37 of 171 celiac patients and changes of "chronic active hepatitis" were detected in five, or $2.3 \%$. In another survey study of 157 patients with "type 1" autoimmune hepatitis and 24 with "type 2 " autoimmune hepatitis for celiac disease, eight of these 181 patients (4\%) were positive for endomysial antibodies, including six with "type 1 " disease (4\%) and two with "type 2 " disease $(8 \%)$. Five of the eight patients, most being asymptomatic, had a duodenal biopsy and all showed typical changes of untreated celiac disease. Effects on symptoms and small bowel biopsy changes caused by drugs (steroids, azathioprine, or both) may have been important, but were not detailed. In a recent study, 47 consecutive patients with autoimmune hepatitis, including 39 with "type 1" disease and eight with "type 2 " disease were evaluated. Anti-IgA tissue transglutaminase and endomysial antibodies were positive in three patients (6.4\%) and small bowel biopsies confirmed the presence of the celiac disease histological changes. Finally, a recent report showed that celiac disease associated antibodies fell in autoimmune liver disease after hepatic transplantation. ${ }^{50}$

Celiac disease and other types of autoimmune liver and biliary tract disease may coexist. A case report of autoimmune cholangitis, ${ }^{51}$ a cholestatic liver disorder with biochemical evidence of cholestasis, histological evidence of inflammatory bile duct damage and an absence of antimitochondrial antbodies, was previously described in a patient with celiac disease. Interestingly, this patient's small intestinal biopsies were reported to be normal without a gluten-free diet while being treated with steroids and azathioprine. In another case, hepatic blood tests were improved without necessitating use of immunosuppressive drugs. ${ }^{52}$

\section{Hemochromatosis or iron overload liver disease}

Celiac disease has been associated with hemochromatosis. ${ }^{53-56}$ Since both are relatively common, however, any association could be coincidental. ${ }^{57}$ Iron absorption largely occurs in the proximal duodenum, the site most often histologically altered in celiac disease. Indeed, "isolated" iron deficiency with anemia may be the initial clinical manifestation of celiac disease. In contrast, in iron overload liver disease, inappropriate iron absorption from the proximal small intestine occurs as body iron stores are markedly increased. In an early study, treatment of celiac disease and improved small intestinal histology led to worsening liver chemisty test values and recognition of occult iron overload liver disease (C282Y-negative), thought to be related to increased intestinal uptake of iron. Another similar case of C282Y-positive hemochromatosis presented with diarrhea, positive antigliadin, and endomysial antibodies. Subsequent small bowel biopsies showed villous atrophy. In this case, phlebotomy treatment was terminated early due to an unanticipated 
rapid fall in serum ferritin. As both disorders are associated with the HLA-region on chromosome 6 , there could be a genetically-based linkage. Later investigations have sought to resolve the possible relationship. In one report, ${ }^{58} \mathrm{HFE}$ (hemochromatosis susceptibility gene) locus mutations were noted to be common in celiac disease, possibly for protection of the celiac from iron deficiency. ${ }^{59} \mathrm{~A}$ later study in an Italian population with untreated celiac disease found that HFE mutations failed to protect against the development of iron deficiency. ${ }^{60}$ In a case study of a patient with homozygous $\mathrm{C} 282 \mathrm{Y}$ and celiac disease, ${ }^{61}$ reduced expression of the divalent metal transporter 1 (DMT1) was observed, but not ferroportin 1 (FP1) or the transferrin receptor 1 (TfR1).

\section{Other liver disorders in celiac disease Fatty liver}

Common causes of hepatic steatosis in celiac disease could include alcohol-induced steatosis, diabetes mellitus, non-alcoholic fatty liver disease, and some forms of drug therapy including corticosteroids. In developing countries, dietary protein deficiency and kwashiorkor may be important causes. Intestinal malabsorption per se has been associated with hepatic steatosis after jejunoileal bypass for morbid obesity $^{62,63}$ and sometimes in those with inflammatory bowel disease, particularly following extensive intestinal resections. ${ }^{64}$ Because celiac disease is now frequently recognized in a clinically occult form before manifestations of marked nutrient depletion are detected, hepatic steatosis is probably less common than in other intestinal diseases.

Several cases of massive fatty infiltration of the liver have been described in adults with celiac disease. ${ }^{65-68}$ Clearly, lesser degrees of hepatic fat deposition may also occur. Most often if massive steatosis is evident, elevated transaminase and alkaline phosphatase activities occur along with alterations in coagulation. However, in most, clinical and biochemical changes attributed to the hepatic steatosis were improved with a gluten-free diet. In a patient with massive hepatic steatosis, ${ }^{67}$ a gluten-free diet for about one year also resulted in normalization of the histologically-defined fatty changes in the liver.

Precise mechanisms involved in fat deposition in the liver are poorly defined. Following jejunoileal bypass, reduced serum levels of some essential and nonessential amino acids may be observed. ${ }^{62,63}$ In addition, changes in serum amino acids have been recorded in patients with starvation-associated kwashiorkor. ${ }^{69,70}$ Based on these other largely nutrition-based disorders, it has been hypothesized that malabsorption in celiac disease might lead to chronic deficiency of a lipotropic factor (eg, choline). With an associated pyridoxine deficiency, hepatic steatosis might occur. ${ }^{71}$ In a recent study, increased intestinal permeability and altered tight junctions were documented in nonalcohol fatty liver disease as well as in primary biliary cirrhosis. ${ }^{72,73}$ The changes appeared to be related, in part, to the presence of small intestinal bacterial overgrowth. Similar permeability changes occur in celiac disease, ${ }^{74-76}$ and may be a factor in development of liver alterations in celiac disease. Further studies are needed to define the pathogenesis for these liver changes in celiac disease.

\section{Hepatic vein obstruction}

Although mesenteric vascular ischemia ${ }^{77}$ and vasculitis ${ }^{78-81}$ have been described in celiac disease, there are also reports of a unusual Budd-Chiari-like syndrome among celiac children from North Africa, particularly Tunisian and Algeria. ${ }^{82,83}$ Hepatic vein obstruction was also documented in three adults. ${ }^{84}$ Deficiencies in protein C and antithrombin III were detected, and malabsorption of vitamin $\mathrm{K}$ in celiac disease was proposed to cause transient protein $\mathrm{C}$ or protein $\mathrm{S}$ deficiencies. Further studies are needed to identify possible factors, either dietary or other environmental agents that may be critical. More recently, a celiac patient with a Budd-Chiari syndrome associated with membranous obstruction of the inferior vena cava treated successfully with percutaneous balloon angioplasty was reported. ${ }^{85}$

\section{Hepatic malignancies}

While hepatocellular cancer has been reported in one patient, cirrhosis was also present. ${ }^{86}$ Occasionally, the liver may be involved with lymphoma, the most frequently detected malignant disorder in celiac disease. ${ }^{87}$ In some, lymphomatous deposits have been detected in the liver, presumably as metastatic lesions. For example, lymphoma in the liver was apparently secondary to jejunal lymphoma, complicating celiac disease. In general, involvement of the liver in celiac disease patients with lymphoma is limited and overshadowed by the clinical course of the intestinal disease. However, in a recent case report, an immune reaction in the splenoportal axis was postulated as a cause for severe portal hypertension. ${ }^{88}$ Primary involvement with hepatic lymphoma may also occur. Indeed, a fulminant cholestatic syndrome has been described in celiac disease, resulting in hepatic failure. ${ }^{89}$ Later investigations showed widespread hepatic involvement with an unusual lymphoid neoplasm classified as hepatosplenic lymphoma, a rare peripheral T-cell lymphoma with rearrangement of the 
gamma-delta T-cell receptor. ${ }^{90,91}$ Similar necrotizing foci in the liver have recently been described in celiac disease with lymph node cavitation. ${ }^{92}$

\section{Liver failure}

In patients from Finland with severe liver failure from a variety of causes in celiac disease, dietary treatment reversed hepatic dysfunction, even in cases where liver transplantation was being considered ${ }^{93}$ In these liver disease patients, congenital hepatic fibrosis, massive hepatic steatosis and progressive hepatitis were noted. In a post-transplant group, $4.3 \%$ had celiac disease discovered before or after transplant. In this group, liver diseases recorded were primary biliary cirrhosis, autoimmune hepatitis, primary sclerosing cholangitis, and congenital hepatic fibrosis. In a recent report, 13 patients are noted with liver failure and celiac disease that had an improvement in liver function with a gluten-free diet. ${ }^{94}$ Causes in this report included primary biliary cirrhosis, primary sclerosing cholangitis, and chronic autoimmune hepatitis. Severe liver disease has also recently been described to complicate childhood celiac disease up to age three years. ${ }^{95}$ Among six cases, four presented with acute liver failure with two requiring hepatic transplantation, prompting the suggestion that new onset celiac disease in children should be evaluated for evidence of liver dysfunction. Finally, children with severe liver disease should also be investigated for untreated celiac disease.

\section{Disclosure}

The author reports no conflicts of interest in this work.

\section{References}

1. Schuppan D, Junker Y, Barisani D. Celiac disease: from pathogenesis to novel therapies. Gastroenterology. 2009;137(6):1912-1933.

2. Hagander B, Berg NO, Brandt L, Norden A, Sjolund K, Stenstam M. Hepatic injury in adult celiac disease. Lancet. 1977;2(8032):270-272.

3. Dickey W, McMillan SA, Collins SA, Watson RG, McLoughlin JC, Love AH. Liver abnormalities associated with celiac sprue. How common are they, what is their significance, and what do we do about them? J Clin Gastroenterol. 1995;20(4):290-292.

4. Gillett HR, Freeman HJ. Serological testing in screening for adult celiac disease. Can J Gastroenterol. 1999;13(3):265-269.

5. Dieterich W, Ehnis T, Bauer M, et al. Identification of tissue transglutaminase as the auto-antigen of celiac disease. Nat Med. 1997; 3(7):797-801.

6. Freeman HJ. Solid-phase ELISA for tissue transglutaminase, an endomysial target for possible serological diagnosis of celiac disease. Can J Gastroenterol. 1998;12(5):115-116.

7. Ludvigsson JF, Elfstrom P, Broome U, Ekbom A, Montgomery SM. Celiac disease and risk of liver disease: a general population-based study. Clin Gastroenterol Hepatol. 2007;5(1):63-69.

8. Volta U, De Franceschhi L, Lari F, Molinaro N, Zoli M, Bianchi FB. Celiac disease hidden by cryptogenic hypertransaminasemia. Lancet. 1998;352(9121):26-29.
9. Bardella MT, Vecchi M, Conte D, et al. Chronic unexplained hypertransaminasemia may be caused by occult celiac disease. Hepatology. 1999;29(3):654-657.

10. Bonamico M, Pitzalis G, Culasso F, et al. Hepatic damage in celiac disease in childhood. Minerva Pediatr. 1986;38(21):959-962. Italian.

11. Jacobsen MB, Fausa O, Elgjo K, Schrumpf E. Hepatic lesions in adult celiac disease. Scand J Gastroenterol. 1990;25(7):656-662.

12. Bardella MT, Fraquelli M, Quatrini M, Molteni N, Bianchi P, Conte D. Prevalence of hypertransaminasemia in adult celiac patients and effect of gluten-free diet. Hepatology. 1995;22(3):833-836.

13. Selcuk H, Kanbay M, Murat K, Yilmaz U. Liver dysfunction after a gluten-free diet in a patient with celiac disease: a new link? Dig Dis Sci. 2006;51(1):213-214.

14. Fine KD, Ogunji F, Saloum Y, Beharry S, Crippin J, Weinstein J. Celiac sprue: another autoimmune syndrome associated with hepatitis C. Am J Gastroenterol. 2001;96(1):138-145.

15. Plot L, Amital H. Infectious associations of celiac disease. Autoimmun Rev. 2009;8(4):316-319.

16. Thevenot T, Boruchowicz A, Henrion J, Nalet B, Moindrot H, ANGH. Celiac disease is not associated with chronic hepatitis C. Dig Dis Sci. 2007;52(5):1310-1312.

17. Thevenot T, Denis J, Jouannaud V, et al. Celiac disease in chronic hepatitis C: a French multicentre prospective study. Aliment Pharmacol Ther. 2007;26(9):1209-1216.

18. Volta U. Pathogenesis and clinical significance of liver injury in celiac disease. Clin Rev Allergy Immunol. 2009;36(1):62-70.

19. Durante-Mangoni E, Iardino P, Resse M, et al. Silent celiac disease in chronic hepatitis $\mathrm{C}$ : impact of interferon treatment on disease onset and clinical outcome. J Clin Gastroenterol. 2004;38(10):901-905.

20. Casella G, Bardella MT, Perego D, Baldini V. Should routine screening for celiac disease be considered before starting interferon/ ribavirin treatment in patients affected by chronic hepatitis C? Eur $J$ Gastroenterol Hepatol. 2004;16(4):429.

21. Garrido C, Vaquer P, Gaya J, et al. Celiac disease of the adult following orthotopic liver transplantation. Description of a case. Gastroenterol Hepatol. 1998;21(3):125-126. Spanish.

22. Logan RF, Ferguson A, Finlayson ND, Weir DG. Primary biliary cirrhosis and celiac disease: an association? Lancet. 1978;1:230-233.

23. Behr W, Barnert J. Adult celiac disease and primary biliary cirrhosis. Am J Gastroenterol. 1986;81:796-799.

24. Olsson R, Kagevi I, Rydberg L. On the concurrence of primary biliary cirrhosis and intestinal villous atrophy. Scand J Gastroenterol. 1982;17(5):625-628.

25. Iliffe GD, Owen DA. An association between primary biliary cirrhosis and jejunal villous atrophy resembling celiac disease. Dig Dis Sci. 1979;24(10):802-806.

26. Freeman HJ. Celiac disease associated with primary cirrhosis in a Coast Salish native. Can J Gastroenterol. 1994;8:105-108.

27. Whitehead EM, Daly JG, Hayes JR. Renal tubular acidosis in association with Sjogren's syndrome, primary biliary cirrhosis, and celiac disease. Ir J Med Sci. 1987;156(4):124-125.

28. Weetman AP. Non-thyroid autoantibodies in autoimmune thyroid disease. Best Pract Res Clin Endocrinol Metab. 2005;19(1):17-32.

29. Fracchia M, Galatola G, Corradi F, et al. Celiac disease associated with Sjogren's syndrome, renal tubular acidosis, primary biliary cirrhosis, and autoimmune hyperthyroidism. Dig Liver Dis. 2004; 36(7):489-491.

30. Anand AC, Elias E, Neuberger JM. End-stage primary biliary cirrhosis in a first generation migrant Asian population. Eur J Gastroenterol Hepatol. 1996;8(7):663-666.

31. Kingham JG, Parker DR. The association between primary biliary cirrhosis and celiac disease: a study of relative prevalences. Gut. 1998;42(1):120-122.

32. Dickey W, McMillan SA, Callender ME. High prevalence of celiac sprue among patients with primary biliary cirrhosis. J Clin Gastroenterol. 1997;25(1):328-329. 
33. Sorensen HT, Thulstrup AM, Blomqvist P, Norgaard B, Fonager K, Ekbom A. Risk of primary biliary cirrhosis in patients with celiac disease: Danish and Swedish cohort data. Gut. 1999;44(5):736-738.

34. Gillett HR, Cauch-Dudek K, Jenny E, Heathcote EJ, Freeman HJ. Prevalence of IgA antibodies to endomysium and tissue transglutaminase in primary biliary cirrhosis. Can J Gastroenterol. 2000;14(8):672-675.

35. Volta U, Rodrigo L, Granito A, et al. Celiac disease in autoimmune cholestatic liver disorders. Am J Gastroenterol. 2002;97(10):2609-2613.

36. Floreani A, Betterle C, Baragiotta A, et al. Prevalence of celiac disease in primary biliary cirrhosis and of antimitochondrial antibodies in adult celiac disease patients in Italy. Dig Liver Dis. 2002;34(4):258-261.

37. Bizzaro N, Villalta D, Tonutti E, et al. IgA and IgG tissue transglutaminase antibody prevalence and clinical significance in connective tissue diseases, inflammatory bowel disease, and primary biliary cirrhosis. Dig Dis Sci. 2003;48(12):2360-2365.

38. Lawson A, West J, Aithal GP, Logan RF. Autoimmune cholestatic liver disease in people with celiac disease: a population-based study of their association. Aliment Pharmacol Ther. 2005;21(4):401-405.

39. Hay JE, Wiesner RH, Shorter RG, LaRusso NF, Baldus WP. Primary sclerosing cholangitis and celiac disease. A novel association. Ann Intern Med. 1988;109(9):713-717.

40. Freeman HJ, Kwan WC. Occult celiac disease associated with lymphocytic sclerosing cholangitis. Can J Gastroenterol. 1994;8: 249-252.

41. Venturini I, Cosenza R, Miglioli L, et al. Adult celiac disease and primary sclerosing cholangitis: two case reports. Hepatogastroenterology. 1998;45(25):2344-2347.

42. Wurm P, Dixon AD, Rathbone BJ. Ulcerative colitis, primary sclerosing cholangitis and celiac disease: two cases and review of the literature. Eur J Gastroenterol Hepatol. 2003;15(7):815-817.

43. Al-Osaimi AM, Berg CL. Association of primary sclerosing cholangitis and celiac disease: a case report and review of the literature. Dig Dis Sci. 2004;49(3):438-443.

44. Wolber R, Owen D, DelBuono L, Appelman H, Freeman HJ. Lymphocytic gastritis in patients with celiac sprue or spruelike intestinal disease. Gastroenterology. 1990;98(2):310-315.

45. Wolber R, Owen D, Freeman HJ. Colonic lymphocytosis in patients with celiac sprue. Hum Pathol. 1990;21(11):1092-1096.

46. Habior A, Rawa T, Orlowska J, et al. Association of primary sclerosis cholangitis, ulcerative colitis, and celiac disease in female siblings. Eur J Gastroenterol Hepatol. 2002;14(7):787-791.

47. Lindberg J, Ahren C, Iwarson S. Intestinal villous atrophy in chronic active hepatitis. Scand J Gastroenterol. 1979;14(8):1015-1016.

48. Swarbrick ET, Fairclough PD, Campbell PJ, Levison DA, Greenwood RH, Baker LR. Celiac disease, chronic active hepatitis, and mesangiocapillary glomerulonephritis in the same patient. Lancet. 1980;2(8203):1084-1085.

49. Volta U, De Franceschi L, Molinaro N, et al. Frequency and significance of anti-gliadin and anti-endomysial antibodies in autoimmune hepatitis. Dig Dis Sci. 1998;43(10):2190-2195.

50. Villalta D, Girolami D, Bidoli E, et al. High prevalence of celiac disease in autoimmune hepatitis detected by anti-tissue transglutaminase autoantibodies. J Clin Lab Anal. 2005;19(1):6-10.

51. Rubio-Tapia A, Abdulkarim AS, Wiesner RH, Moore SB, Krause PK, Murray JA. Celiac disease autoantibodies in severe autoimmune liver disease and the effect of liver transplantation. Liver Int. 2008;28(4):467-476.

52. Gogos CA, Nikolopoulou V, Zolota V, Siampi V, Vagenakis A. Autoimmune cholangitis in a patient with celiac disease: a case report and review of the literature. J Hepatol. 1999;30(2):321-324.

53. Sedlack RE, Smyrk TC, Czala AJ, Talwalkar JA. Celiac diseaseassociated autoimmune cholangitis. Am J Gastroenterol. 2002; 97(12):3196-3198.

54. Morris WE Jr. Hemochromatosis and celiac sprue. Case report. J Fla Med Assoc. 1993;80(4):243-245.

55. Heneghan MA, Feeley KM, Stevens FM, Little MP, McCarthy CF. Precipitation of iron overload and hereditary hemochromatosis after successful treatment of celiac disease. Am J Gastroenterol. 2000; 95(1):298-300.
56. Turcu A, Leveque L, Bielefeld P, Besancenot JF, Hillon P. Adult celiac disease and hemochromatosis. Am J Gastroenterol. 2000;5(12): 3661-3662.

57. Singhai A, Moreea S, Reynolds PD, Bzeizi KI. Celiac disease and hereditary hemochromatosis: association and implications. Eur $J$ Gastroenterol Hepatol. 2004;16(2):235-237.

58. Leyden J, Kelleher B, Ryan E, Barrett S, O'Keane JC, Crowe J. The celtic coincidence - the frequency and clinical characterization of hereditary hemochromatosis in patients with celiac disease. Ir J Med Sci. 2006;175(1):32-36.

59. Butterworth JR, Cooper BT, Rosenberg WM, et al. The role of hemochromatosis susceptibility gene mutations in protecting against iron deficiency in celiac disease. Gastroenterology. 2002;123(2):444-449.

60. Bowlus CL, Lie BA, Ravine D, Darke C. Discussion of the role of hemochromatosis susceptibility gene mutation in protecting against iron deficiency in celiac disease. Gastroenterology. 2003;124(5):1562-1564.

61. Barisani D, Ceroni S, Del Bianco S, Meneveri R, Bardella MT. Hemochromatosis gene mutations and iron metabolism in celiac disease. Haematologica. 2004;89(11):1299-1305.

62. Geier A, Gartung C, Theurl I, et al. Occult celiac disease prevents penetrance of hemochromatosis. World J Gastroenterol. 2005; 11(21):3323-3326.

63. Holzbach RT. Hepatic effects of jejunoileal bypass for morbid obesity. Am J Clin Nutr. 1977;30(1):43-52.

64. Moxley RT, Pozefsky T, Lockwood DH. Protein nutrition and liver disease after jejunoileal bypass for morbid obesity. $N$ Engl $J$ Med. 1974;290(17):921-926.

65. Kern F. Hepatobiliary disorders in inflammatory bowel disease. Prog Liver Dis. 1976;5:575-589.

66. Van Tongeren IH, Breed WP, Corstens FH. Fatty liver and malabsorption. Folia Med Neerl. 1972;15(4):246-258.

67. Capron JP, Sevenet F, Quenum C, Doutrellot C, Capron-Chivrac D, Delmarre J. Massive hepatic steatosis disclosing adult celiac disease: report of a case and review of the literature. Gastroenterol Clin Biol. 1983;7(3):256-260. French.

68. Naschitz JE, Yeshurun D, Zuckerman E, Arad E, Boss JH. Massive hepatic steatosis complicating adult celiac disease: report of a case and review of the literature. Am J Gastroenterol. 1987;82(11):1186-1189.

69. Sood A, Midha V, Sood N. Nonalcoholic steatohepatitis, obesity, and celiac disease. Indian J Gastroenterol. 2003;22(4):156.

70. Padilla H, Sanchez A, Powell RN, et al. Plasma amino acids in children from Guadalajara with kwashiorkor. Am J Clin Nutr. 1971;24(3):353-357.

71. Freeman HJ, Kim YS, Sleisenger MH. Protein digestion and absorption. Normal mechanisms and protein-energy malnutrition. Am J Med. 1979;67(6):1030-1036.

72. Miele L, Valenza V, La Torre G, et al. Increased intestinal permeability and tight junction alterations in nonalcoholic fatty liver disease. Hepatology. 2009;49(6):1877-1887.

73. Feld JJ, Meddings J, Heathcote EJ. Abnormal intestinal permeability in primary biliary cirrhosis. Dig Dis Sci. 2006;51(9):1607-1613.

74. Fasano A, Not T, Wang W, et al. Zonulin, a newly discovered modulator of intestinal permeability, and its expression in celiac disease. Lancet. 2000;355(9214):1518-1519.

75. Pizzuti D, Bortolami M, Mazzon E, et al. Transcriptional downregulation of tight junction protein $\mathrm{ZO}-1$ in active celiac disease is reversed after a gluten-free diet. Dig Liver Dis. 2004;36(5):337-341.

76. Lammers KM, Lu R, Brownley J, et al. Gliadin induces an increase in intestinal permeability and zonulin release by binding to the chemokine receptor CXCR3. Gastroenterology. 2008;135(1):194-204.

77. Upadhyay R, Park RH, Russell RI, Danesh JJ, Lee FD. Acute mesenteric ischemia: a presenting feature of celiac disease? Br Med J (Clin Res Ed). 1987;295(6604):958-959.

78. Does WF, Evans D, Hobbs JR, Booth CC. Celiac disease, vasculitis, and cryoglobulinemia. Gut. 1972;13(2):112-123.

79. Meyers S, Dikman S, Spiera H, Schultz N, Janowitz HD. Cutaneous vasculitis complicating celiac disease. Gut. 1981;22(1):61-64. 
80. Alegre VA, Winkelmann RK, Diez-Martin JL, Banks PM. Adult celiac disease, small and medium vessel cutaneous necrotizing vasculitis, and T cell lymphoma. J Am Acad Dermatol. 1988;19(5 Pt 20):973-978.

81. Simila S, Kokkonen J, Kallionen M. Cutaneous vasculitis as a manifestation of celiac disease. Acta Pediatr Scand. 1982;71(6): 1051-1054.

82. Gentil-Kocher S, Bernard O, Brunelle F. Budd-Chiari syndrome in children: report of 22 cases. J Pediatr. 1988;113(1 Pt 1):30-38.

83. Hamdi A, Ayachi R, Saad H, Gargouri R, Zouari K, Chebbah MS. Hemiplegia revealing Budd-Chiari syndrome associated with celiac disease in an infant. Presse Med. 1990;19(21):1011-1012. French.

84. Marteau P, Cadranel JF, Messing B, Gargot D, Valla D, Rambaud JC. Association of hepatic vein obstruction and celiac disease in North African subjects. J Hepatol. 1994;20(5):650-653.

85. Martinez F, Berenguer M, Prieto M, Montes H, Rayon M, Berenguer J. Budd-Chiari syndrome caused by membranous obstruction of the inferior vena cava associated with celiac disease. Dig Liver Dis. 2004;36(2):157-162.

86. Pollock DJ. The liver in celiac disease. Histopathology. 1977;1(6): 421-430.

87. Freeman HJ. Lymphoproliferative and intestinal malignancies in 214 patients with biopsy-defined celiac disease. J Clin Gastroenterol. 2004;38(5):429-434.

88. Zamani F, Amiri A, Shakeri R, Zare A, Mohamadnejad M. Celiac disease as a potential cause of idiopathic portal hypertension: a case report. J Med Case Reports. 2009;3:68.
89. Freeman HJ. Fulminant liver failure with necrotizing foci in the liver, spleen, and lymph nodes in celiac disease due to malignant lymphoma. Can J Gastroenterol. 1996;10(4):225-229.

90. Harris NL, Jaffe ES, Stein H, et al. A revised European-American classification of lymphoid neoplasms: a proposal from the International Lymphoma Study Group. Blood. 1994;84(5):1361-1392.

91. Farcet J, Gaulard P, Marolleau J, et al. Hepatosplenic T-cell lymphoma: sinusal/sinusoidal localization of malignant cells expressing the T-cell receptor gamma-delta. Blood. 1990;75(11):2213-2219.

92. Cornelis T, Hiele M, Vermeire S, Libbrecht L, Verslype C. A unique combination of celiac disease, mesenteric lymph node cavitation, splenic atrophy, and necrotizing hepatitis. Acta Gastroenterol Belg. 2008;71(2):267-270.

93. Kaukinen K, Halme L, Collin P, et al. Celiac disease in patients with severe liver disease: gluten-free diet may reverse hepatic failure. Gastroenterology. 2002;122(4):881-888.

94. Stevens FM, McLoughlin RM. Is celiac disease a potentially treatable cause of liver failure? Eur $J$ Gastroenterol Hepatol. 2005;17(10):1015-1017.

95. Casswall TH, Papadogiannakis N, Ghazi S, Nemeth A. Severe liver damage associated with celiac disease: findings in six toddler-aged girls. Eur J Gastroenterol Hepatol. 2009;21(4):452-459.
Clinical and Experimental Gastroenterology

\section{Publish your work in this journal}

Clinical and Experimental Gastroenterology is an international, peerreviewed, open access journal, publishing all aspects of gastroenterology in the clinic and laboratory, including: Pathology, pathophysiology of gastrointestinal disease; Investigation and treatment of gastointestinal disease; Pharmacology of drugs used in the alimentary tract;

\section{Dovepress}

Immunology/genetics/genomics related to gastrointestinal disease. This journal is indexed on CAS. The manuscript management system is completely online and includes a very quick and fair peer-review system. Visit http://www.dovepress.com/testimonials.php to read real quotes from published authors.

Submit your manuscript here: http://www.dovepress.com/clinical-and-experimental-gastroenterology-journal 